\title{
AFETIVIDADES EM FLUXO Um debate sobre a importância da língua de acolhimento para a sociabilidade do migrante

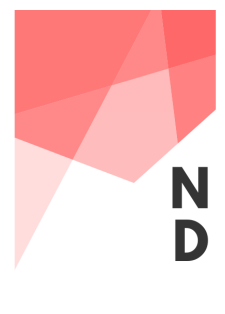

\author{
AFFECTIVITIES IN FLOW \\ A debate on the importance of the host country's \\ language for the migrant's sociability
}

\author{
Lara Noronha Xavier \\ Universidade de Brasília \\ Departamento de Antropologia | Brasília, Brasil \\ laranoronha123@gmail.com | ORCID iD: 0000-0002-3875-6925
}

\begin{abstract}
Resumo
A presente pesquisa visa compreender como a questão linguística pode se tornar tanto uma barreira quanto uma ferramenta de agregação. Dessa forma, a partir de autores como Anderson (2006) e Fanon (2008) entende-se como a formação da identidade nacional está diretamente ligada ao sistema de exclusão pela linguagem, se associando com Fanon (2008) quando o autor afirma as dimensões da fala dos migrantes antilhanos localizados na França e a presença do pètit-nègre. Ao pensar a língua como ferramenta de agregação, trago para o debate a minha pesquisa de campo dentro do projeto "PROAcolher: Português para migrantes e refugiados em situação de risco". Analiso como transformar o que era excludente em agregador, e o papel das trocas afetivas nesse processo.
\end{abstract}

\section{Palavras-chave}

Migração; Língua de Acolhimento; Afeto; Exclusão; Sociabilidade.

\begin{abstract}
The present research aims to understand how the language issue can become both a barrier and a tool for aggregation. Thus, based on authors such as Anderson (2006) and Fanon (2008), it is observed how the formation of national identity is directly linked to the system of exclusion through language, following Fanon (2008) in his reflections on the speech of Antillean migrants located in France and the presence of the petit-nègre. In thinking about language as a tool for aggregation, I bring to the debate my field research within the project "PROAcolher: Portuguese for migrants and refugees at risk". I analyze how to transform what was excluding into aggregating, and the role of affective exchanges in this process.
\end{abstract}

\section{Keywords}

Migration; Language, Affection; Exclusion;

Sociability 


\section{Introdução}

$\mathrm{O}$

presente artigo visa compreender como as afetividades construídas no cotidiano dos programas de português como língua de acolhimento influenciam na sociabilidade do migrante no novo local. Tendo em vista que o sujeito em mobilidade necessita da língua para conseguir se comunicar no país de destino, ainda que essa interação seja limitada ao seu lugar trabalho ou em situações da vida prática, como fazer compras em supermercados e na burocracia estatal.

Metodologicamente, esse trabalho se deu em duas etapas. $\mathrm{Na}$ primeira, inseri-me em campo sendo monitora do projeto PROAcolher situado nas dependências do Núcleo de Pesquisa de Português para Estrangeiros (NEPPE) da Universidade de Brasília. No segundo momento, fiz entrevistas com os professores desse projeto com o objetivo de compreender suas visões de acolhimento, como eles enxergam as afetividades entre docentes e discentes e sua importância para o processo de sociabilidade.

A pesquisa possui um duplo objetivo. Primeiramente, visa compreender como são construídos esses afetos e qual sua função social no processo de sociabilidade do migrante. Posteriormente, pretende analisar a visão dos professores sobre essas afetividades e como eles imaginam que ela interfere, ou não, na vida social desses indivíduos, tendo em vista que alguns deles criam vínculos afetivos reais com seus alunos. Dentro da pesquisa, a afetividade é trazida como em Mosquera e Strobaus (2006): relacionamentos recíprocos entre o grupo de alunos e as professoras, sendo assim a responsável por atribuir significação aos objetos apresentados dentro de sala de aula. ${ }^{1}$ Pensando sobre esse conceito juntamente com os professores do PROAcolher, entende-se que dentro do projeto a troca afetiva se caracteriza por respeitar e entender as demandas dos alunos para que assim haja o acolhimento não apenas linguístico mas também social.

\section{O fluxo de línguas e suas formas de poder}

Antes de adentrar o campo da afetividade e da língua de acolhimento, se faz necessário compreender como são

\footnotetext{
' Esse pensamento de forma de afetividade também pode ser encontrado em Ribeiro e Jutras (2006), os autores discorrem que as representações sociais assumidas pelos professores moldam os processos de afetividade.
} 
construídas as expressões linguísticas e como elas influem no processo de socialização dos indivíduos. De acordo com Anderson (2006), as linguagens impressas criam três pilares principais para a formação da identidade nacional. $\mathrm{O}$ primeiro é a criação de campos unificados de troca e comunicação, assim, limita-se pelo idioma quem estará ou não englobado pela língua. O segundo é a ideia de fixação de uma expressão linguística, dessa forma, se estabelece qual é o conjunto de símbolos e significados que serão aceitos naquela comunidade. E, por fim, criam-se línguas de poder, estabelecendo-se modos de falar esse idioma que são válidos ou não, e assim aceitando apenas os que são convenientes para aquele estado-nação.

Pensando sobre a criação dessa modalidade de forma de poder a partir do modelo linguístico utilizado, Fanon (2008) afirma que falar é existir para o outro, é assumir uma forma cultural. Por isso, o autor aborda que existem duas dimensões na fala do negro, a primeira é como ele se expressa com o seu semelhante e a segunda é como ele se comunica com o branco. Sabendo que existem formas de poder na língua, o negro tem que assumir distintas formas de comunicação para tentar ser integrado na sociedade.

Foucault (1982) tem um pensamento que coincide com Fanon (2008) ao abordar que a comunicação é sempre um modo de ação de formas de poder, sendo por ela expressada a diferença entre classes. De acordo com o autor, as formas de poder são reforçadas em ações rotineiras dos indivíduos, pois é nesses momentos que esses sujeitos são categorizados e marcados por sua individualidade e identidade. Esse pensamento foucaultiano de enquadramento é trazido com excelência por Fanon (2008) quando o autor aborda o petit-nègre, forma linguística do francês normalmente utilizada por antilhanos. $\mathrm{O}$ autor afirma que os antilhanos quando estão na França falam uma versão da língua gramaticalmente perfeita, porém, são enquadrados em um local hierárquico inferior por causa de sua aparência física. Assim, não importa o quão perfeito seja o francês do antilhano, o cidadão francês sempre o irá responder em petit-négre para, dessa forma, mostrar para aquele indivíduo qual é o seu local naquela sociedade.

Com a exposição feita nessa seção percebe-se, a partir da reflexão foucaultiana, que o Estado integra os indivíduos que se encaixam em algumas condições e que se submetem a uma série de padrões específicos. Uma dessas exigências é exatamente o idioma, que de acordo com Anderson (2006) é um dos fatores de 
criação do estado- nação e é trazido por Fanon (2008) e Foucault (1982) como necessidade linguística para a sociabilidade, e também como forma de poder. Na língua de acolhimento, há uma tentativa de transformação do idioma, normalmente tratado como forma de poder e repressão para reconhecê-lo como modo de integração e inserção.

\section{A língua de acolhimento e a afetividade}

Primeiramente, gostaria de apresentar o programa no qual realizei meu campo. O PROAcolher foi fundado pela professora Lucia Maria de Assunção Barbosa, atual coordenadora do projeto, e tem seu funcionamento nas dependências do NEPPE-UnB ${ }^{2}$. Os estudantes são divididos em três módulos (acolher 1, 2 e 3), e os cursos são ministrados no período noturno, possuindo três encontros de duas horas por semana. Dentro de sala de aula, para que possa ocorrer um melhor atendimento das demandas dos estudantes, são necessárias duas professoras e uma monitora por turma, além disso, são oferecidas monitoras para retirada de dúvidas uma hora antes do início das aulas. Outra atividade oferecida pelo projeto são oficinas tanto para questões linguísticas, como pronunciação, quanto laborais, como de produção de currículo.

O projeto foi fundado no ano de 2013, a partir de uma percepção de demanda de cursos de português gratuitos para migrantes e refugiados, sendo que até aquele momento apenas eram ofertados cursos pagos no NEPPE. O projeto funciona inteiramente com trabalho voluntário e em 7 anos já possuiu cerca de 200 colaboradores. A metodologia de acolhimento é diferenciada por não possuir a gramática como ponto principal da língua, mas sim a fala e a compreensão da mesma, tendo como objetivo quebrar as barreiras entre indivíduo e idioma, facilitando a sociabilidade do migrante. ${ }^{3}$ No segundo semestre de 2019, quando voluntariei como monitora do projeto, foram atendidos cerca de 100 estudantes, em sua maioria advindos de Gana, Síria, Bangladesh e Venezuela.

Para introduzir a língua de acolhimento se faz necessário compreender o porquê da criação desse termo no lugar de língua estrangeira. Essa dualidade é colocada por Ferreira (2017), a

\footnotetext{
${ }^{2}$ Núcleo de Ensino e Pesquisa em Português para Estrangeiros.

Informações retiradas do site oficial do projeto: https://proacolherunb.wixsite.com/proacolher
} 
autora afirma que a segunda traz uma sensação de isolamento e exclusão, enquanto a primeira tem como objetivo tornar os migrantes cidadãos. Dessa forma, percebe-se que a língua estrangeira não traz a possibilidade de apropriação do idioma, ou seja, a língua nunca será daquele indivíduo que está aprendendo. Relacionando Grosso (2010) com essa diferenciação feita por Ferreira (2017), é possível perceber que as formas de ensino também estão ligadas a formas de poder, pois a língua estrangeira está, na maioria das vezes, ligada à do colonizador, ou seja, afirmando um sistema de opressão.

Antes de adentrar na metodologia desse ensino, irei diferenciá-la da língua estrangeira. Tendo em vista que a primeira é ensinada quando o migrante já se encontra no país de destino, assim, visando integrá-lo social e laboralmente, compreendendo suas limitações e tentando abarcar suas necessidades sociais. No caso da língua estrangeira, de acordo com Ferreira (2017), essa traz uma noção de exclusão e isolamento, ela é ensinada como idioma do outro, de uma sociedade da qual aquele indivíduo não está em contato. E, também, costuma ser ensinada enquanto o sujeito ainda está no seu país de origem, não tendo urgência para a inserção social daquele estudante.

Para entender melhor as bases do ensino de língua de acolhimento, Barbosa e Ruano (2016) trazem dois pilares principais para essa modalidade, a urgência e a afetividade. $\mathrm{O}$ primeiro se faz presente pelo fato de o indivíduo necessitar daquele idioma para poder realizar atividades rotineiras, a indispensabilidade daquela língua torna seu aprendizado urgente. E a afetividade é a forma como o professor consegue enxergar as necessidades dos indivíduos e fazer com que eles se sintam bem naquele ambiente, para que assim compartilhem suas vivências no país de acolhida e compreendam melhor sua cultura e formas de vida e expressão.

As trocas afetivas, como pratos de comida típicos de seus países que os alunos trazem para as aulas até caronas que os alunos que trabalham como uber oferecem para as professoras são trazidas por Grosso (2010) como transformadoras das concepções sobre a língua do país de destino e criam uma outra visão do migrante para com essa sociedade. Assim, as afetividades ultrapassam as barreiras profissionais, fazendo com que esses estudantes se sintam à vontade para ter trocas tanto de vivência quanto de conhecimento com seus professores. Dessa forma, esses laços são projetados para fora de sala de aula, e essa 
conexão entre docente-discente também se torna uma relação de amizade, de alguém a quem se pode confiar vivências, frustrações e inseguranças.

Para articular minha pesquisa de campo à discussão, irei apresentar os dados que coletei durante as entrevistas. Sempre que possuir um caso etnográfico ou uma situação que vivenciei dentro de sala de aula, e que seja parecida com o que o professor aborda em seu relato, irei trazê-la para debate.

Ao pensar essas afetividades juntamente com a desumanização de corpos específicos de Fanon (2008), Marília, uma professora do projeto, afirmou que o ambiente do projeto de língua de acolhimento é um espaço que tenta reumanizar esse migrante, não somente pela língua, mas também pelas interações sociais. Por ser um ambiente em que se encontram indivíduos com vivências parecidas dentro do país de acolhida, eles se sentem confortáveis para relatar suas frustrações e seus sucessos. Marília também aborda que essa socialização ocorre via acolhimento, pois se aquele ambiente não fosse construído para tal, eles não estariam à vontade com essa troca, logo, não haveria essa tentativa de reumanização, pois, em concomitância com o pensamento fanoniano, a professora pensa que esse processo vai além da questão linguística, e tem como seu principal obstáculo o preconceito racial.

Para exemplificar os sucessos e frustrações trazidos por Marília, coloco no debate duas experiências contadas pela professora. A primeira foi de um aluno de Bangladesh, Ian, que conseguiu a naturalização brasileira, a qual tem como requisito o aprendizado da língua portuguesa. De acordo com o estudante, seu processo foi facilitado por possuir o certificado de conclusão de curso do PROAcolher. O outro relato que a professora fez foi sobre traumas com a sociedade brasileira, ela conta que em uma aula sobre a história do Brasil e a construção da sociedade brasileira, uma aluna senegalesa levantou a mão e falou que o brasileiro é preconceituoso, e por diversas vezes ela havia perdido empregos por causa de sua nacionalidade e sua cor. A estudante contou que em sua última entrevista de trabalho havia sido a primeira a chegar e a última a ser entrevistada, isso a deixava muito chateada e inquieta, pensando o porquê aquelas pessoas valiam mais do que ela, porque sua cor e sua nacionalidade a faziam tão diferente. Aqui, percebemos tanto os sucessos que o projeto traz para o processo migratório de seus estudantes, mas também as frustrações e traumas que os migrantes possuem dentro do país de "acolhida". 
A partir do exposto pela professora do PROAcolher e dos relatos trazidos, consegue-se perceber que o ambiente do projeto é um espaço não apenas de aprendizado, mas também de troca afetiva. É o fluxo dessas afetividades que faz com que o ensino da cultura e da língua se tornem mais efetivos. Em muitos casos, esses indivíduos, desumanizados pela sociedade, possuem o momento de sala de aula para interação social, porque no restante do seu dia constituem apenas relações trabalhistas. Logo, esse acolhimento é necessário para que o migrante consiga se apropriar da língua do país de destino e compreendê-la também como sua, dessa forma, o integrando a sociedade.

Agregando Hall (1992) ao relato da professora, o acolhimento se torna ferramenta para a construção de novas identidades, é a partir da troca entre alunos e professores que irão ser apreendidas novas culturas e novas formas de viver e pensar. Assim, seguindo a noção de identidade pós-moderna colocada pelo o autor, são construídas novas identidades a partir das interações sociais do indivíduo, dessa forma, fazendo com que não só o migrante crie novas modalidades identitárias, mas também que o professor reconstrua algumas de suas concepções a partir da troca afetiva e de conhecimento.

Por fim, é possível perceber que esse acolhimento por vias linguísticas, perpassa questões sociais e raciais que são colocadas dentro da sociedade de acolhida. A partir dessa convivência, o professor consegue perceber a especificidades de cada aluno e qual a necessidade de cada um, tanto na área linguística quanto laboral e social. O projeto se torna um local de apoio para os migrantes, no qual eles podem se expressar e socializar com seus colegas e professores, e a partir dessa interação, possam ter uma inserção social mais efetiva.

\section{Considerações finais}

Para retomar a questão principal, é preciso compreender que o ensino da língua de acolhimento não utiliza uma metodologia convencional de estudos linguísticos, mas é baseada em trocas afetivas, que podem auxiliar os migrantes a mapearem as diferenças socioculturais entre os países de origem e destino e fazer com que eles construam sua própria identidade nessa nova localidade. Outro fator importante para entendermos esses fluxos é a tentativa desses projetos de reumanizar corpos que estão sofrendo desumanizações em sua vivência no país de destino, o acolhimento também tem como objetivo mostrar para 
esses migrantes que eles são importantes e fazem parte daquele constructo social, e devem se sentir como participantes daquela sociedade.

Por fim, é a afetividade, baseada no respeito e no entendimento das necessidades desses migrantes, que torna possível o acolhimento, pois sem ela os estudantes não se sentiriam à vontade para realizar trocas entre professores e estudantes, dessa forma, causando uma falha nesse processo de acolhida. É a partir da afetividade que se constrói o conforto e a confiança da troca, possibilitando, assim, um acolhimento efetivo.

\section{Referências Bibliográficas:}

ANDERSON, Benedict. 2006. Imagined Communities: Reflections on the Origin and Spread of Nationalism. Londres: Verso.

BARBOSA, Lucia Maria; RUANO, Bruna. 2016. "Acolhimento, Sentidos e Práticas de ensino de português para migrantes e refugiados, na Universidade de Brasília e na Universidade Federal do Paraná." In: José Antônio Peres Gediel e Gabriel Gualano de Godoy (org.). Refúgio e Hospitalidade. Curitiba: Kairós Edição. pp. 321-337.

FANON, Frantz. 2008. Pele negra, máscaras brancas. Salvador: EDUFBA.

FERREIRA, Giselda. 2017. "O português como língua de acolhimento e interação: a busca pela autonomia por pessoas em situação de refúgio no Brasil." Cadernos de PósGraduação em Letras 1(17): 118-134.

FOUCAULT, Michel. 1982. "The subject and power." Critical Inquiry 8: 777-795.

GROSSO, Maria José. 2010. "Língua de acolhimento, língua de integração." Horizontes de Linguística Aplicada 2(9): 61-77.

HALL, Stuart. 1992. A identidade cultural na pós-modernidade. Rio de Janeiro: DP\&A Editora.

MOSQUERA, Juan José; STROBAUS, Claus. 2006. "Afetividade: A manifestação de sentimentos na educação." Educação, ano XXIX, 1(58): 123-133.

RIBEIRO, Marinalva; JUTRAS, France. 2006. "Representações sociais de professores sobre afetividade". Estudos de psicologia, 23(1): 39-45. 
Enviado: 29 de julho de 2020 Aceito: 26 de outubro de 2020 